\title{
POPULASI BEKANTAN (Nasalis larvatus) DI KAWASAN HUTAN MANGROVE SUNGAI SETINGGA ASIN DESA SEBUBUS KECAMATAN PALOH KABUPATEN SAMBAS
}

\author{
(Population Of Bekantan (Nasalis larvatus) In The Mangrove Forest Setingga Asin River \\ Sebubus Village Paloh District Sambas Regency)
}

\author{
Ayu Dewi Puspitasari, Erianto, Slamet Rifanjani \\ Fakultas Kehutanan Universitas Tanjungpura Pontianak. Jl. Daya Nasional Pontianak 78124 \\ Email : ayudwipuspitasari1394@gmail.com
}

\begin{abstract}
Bekantan or Proboscis Monkey (Nasalis larvatus) is a herbivorous primate that occupies riparian areas, mangrove forests and coastal forests in Kalimantan. This species is an endemic primate on Kalimantan Island which has been declared as one of the protected species by the Government of Indonesia based on the Minister of Environment and Forestry Regulation number P.106 of 2018 concerning protected plant and animal species. Bekantan's main habitat in the form of mangrove swamp forest areas has now been opened due to human activities so that habitats suitable for the life of the proboscis monkey are reduced. This research was conducted in the mangrove forest of Sebubus Village, Paloh Subdistrict, Sambas Regency for 2 weeks effectively in the field to observe and count the number of Bekantan. Starting from September 16, 2018 until completion. This study aims to record the estimated population of Bekantan (Nasalis larvatus) in the mangrove forest area of Sungai Setingga Asin Sebubus Village, Paloh District, Sambas Regency. The research method used is the river survey method. Bekantan population calculation is done by the King method. Based on observations with 6 replications morning and evening. The area of the study area of 14.91 ha showed that there were 35.8 individuals and 1 group of proboscis monkey with a population density of 1.2 individual probes / ha and a group density of 0.03 groups / ha of proboscis.
\end{abstract}

Keyword : mangrove forest Sebubus, proboscis monkey, river survey,.

\section{PENDAHULUAN}

Habitat bekantan sebagian besar berada di wilayah lahan basah, daerah riparian dan mangrove. Hutan mangrove di Desa Sebubus merupakan salah satu habitat bekantan yang berada di Sambas. Desa Sebubus Kecamatan Paloh Kabupaten Sambas merupakan daerah pesisir yang berbatasan langsung dengan Laut Natuna yang terdapat satwa endemik bekantan di vegetasi hutan mangrove. Secara garis besar hutan mangrove mempunyai banyak fungsi, selain sebagai pelindung lingkungan sekitar, hutan mangrove juga berfungsi sebagai kawasan untuk berlindung, bersarang, serta berkembang biak bagi hewan primata seperti bekantan.

Maraknya pembukaan lahan sampai ke lokasi mangrove dapat menjadi penyebab berkurangnya populasi bekantan. Menyikapi keberadaan hutan mangrove di Desa Sebubus sebagai objek wisata yang digemari oleh masyarakat sekitar maupun masyarakat dari luar daerah. Hal ini menyebabkan banyaknya masyarakat yang mengetahui keberadaan satwa endemik tersebut membuat masyarakat tertarik 
untuk mengekspos satwa tersebut, sehingga satwa tersebut merasa terusik keberadaannya. Gangguan lainnya yaitu masih ada sebagian masyarakat yang menebang pohon untuk dijadikan lahan tambak dan pembukaan lahan untuk areal persawahan.

Penelitian ini bertujuan untuk memprediksi jumlah populasi Bekantan (Nasalis larvatus) di kawasan hutan mangrove Sungai Setingga Asin Desa Sebubus Kecamatan Paloh Kabupaten Sambas. Penelitian ini juga diharapkan dapat memberikan data dan informasi mengenai jumlah populasi bekantan yang ada di hutan mangrove Desa Sebubus agar dapat digunakan sebagai acuan untuk peneliti selanjutnya.

\section{METODE PENELITIAN}

Penelitian ini dilaksanakan di hutan mangrove Desa Sebubus Kecamatan Paloh Kabupaten Sambas Mulai dari tanggal 16 September 2018 sampai selesai, selama \pm 2 minggu efektif di lapangan untuk mengamati dan menghitung jumlah bekantan dan dilanjutkan dengan analisis data yang telah dicatat pada saat pengamatan. Objek penelitian ini adalah Bekantan (Nasalis Larvatus) yang ditemukan di lokasi pengamatan. Alat dan bahan yang digunakan dalam penelitian ini adalah kamera DSLR (Digital Single Lens Reflector), binocular, counter, GPS (Global Postioning System), tally sheet, Peta kawasan hutan Mangrove Desa Sebubus, jam dan sampan.

Metode penelitian yang digunakan adalah metode river survey (Sha et al., 2008). Metode river survey yaitu metode survei dengan menggunakan perahu menyusuri sepanjang sungai pada areal yang diteliti, dalam hal ini Sungai Setingga Asin. Titik awal jalur pengamatan diletakkan di bagian hulu sungai secara purposive kemudian menggunakan sampan mengikuti sungai ke arah hilir. Panjang jalur pengamatan yaitu 2,98 km yang dibagi menjadi 3 jalur yaitu jalur $\mathrm{A}, \mathrm{B}$ dan $\mathrm{C}$ dengan masing-masing panjang jalur adalah 993,3 m. Pengamatan dilakukan dengan 6 kali ulangan pada setiap jalur pengamatan, waktu pengamatan dilakukan sesuai waktu aktif satwa dimulai dari pukul 05.00 sampai pukul 09.00 dan sore pukul 16.30 sampai 18.30. Selama waktu pengamatan tersebut dicatat jumlah individu, jenis kelamin, waktu perjumpaan dan kondisi lingkungan habitat bekantan. Pengamatan bekantan dilakukan dengan jarak pandang 50 meter ke kanan dan 50 meter ke kiri sungai.

Data yang dikumpulkan dimasukkan dalam tabel dan kemudian dihitung jumlah individu dan jumlah kelompok populasi. Hasil pengamatan dianalisis untuk mendapatkan kepadatan populasi, dihitung dengan menggunakan metode King (Tobing, 2008).

$$
\mathbf{D}=\sum \mathbf{X}_{\mathbf{i}} / \mathbf{2 . L} \cdot \mathbf{w}
$$

Dimana :

$\mathrm{D}=$ Kepadatan (individu $/ \mathrm{km}^{2}$ )

$\Sigma X_{\mathrm{i}}=$ Jumlah individu suatu jenis (individu) yang dijumpai pada kontak ke-i

$\mathrm{L} \quad=$ Panjang transek jalur pengamatan $(\mathrm{km})$

$\mathrm{w}=$ Lebar kiri atau kanan jalur pengamatan

(m) 
Guna mengetahui perkiraan jumlah populasi bekantan digunakan rumus sebagai berikut :

$$
\mathbf{P}=\mathbf{D} \times \mathbf{L R E P}
$$

Dimana :

$\mathrm{P}=$ Estimasi populasi (individu)

$\mathrm{D}=$ kepadatan populasi (individu $/ \mathrm{km}^{2}$ )

$\mathrm{L}_{\mathrm{REP}}=$ luas habitat reprensentatif $\left(\mathrm{km}^{2}\right)$

\section{HASIL DAN PEMBAHASAN}

A. Jumlah Individu dan kelompok Bekantan (Nasalis larvatus).

Jumlah individu bekantan yang terlihat pada saat penelitian pada masing-masing jalur dapat dilihat pada tabel 1 .

Tabel 1. Jumlah individu bekantan (Nasalis larvatus) pada jalur A. (The number of Bekantan (Nasalis larvatus) on line A).

\begin{tabular}{cccc}
\hline Ulangan & Waktu penelitian & $\begin{array}{c}\text { Luas areal penelitian } \\
(\mathrm{Ha})\end{array}$ & Jumlah individu \\
\hline 1 & Pagi & 4,97 & 0 \\
2 & Sore & 4,97 & 0 \\
& Pagi & 4,97 & 15 \\
3 & Sore & 4,97 & 30 \\
& Pagi & 4,97 & 3 \\
\multicolumn{2}{c}{ Sore } & 4,97 & 11 \\
\hline \multicolumn{2}{c}{ Jumlah rata-rata } & 4,97 & 10,6 \\
\hline \multicolumn{2}{c}{ Jumlah perjumpaan $\quad$ dengan } & individu. Berdasarkan data tersebut \\
bekantan yang paling sedikit dijumpai & diperkirakan jumlah bekantan di jalur A \\
pada jalur A adalah 5 individu, & dengan luas areal penelitian 4,97 Ha \\
sedangkan jumlah tertinggi adalah 30 & adalah sekitar 10,6 individu.
\end{tabular}

Tabel 2. Jumlah individu bekantan (Nasalis larvatus) pada jalur B. (The number of Bekantan (Nasalis larvatus) on line B).

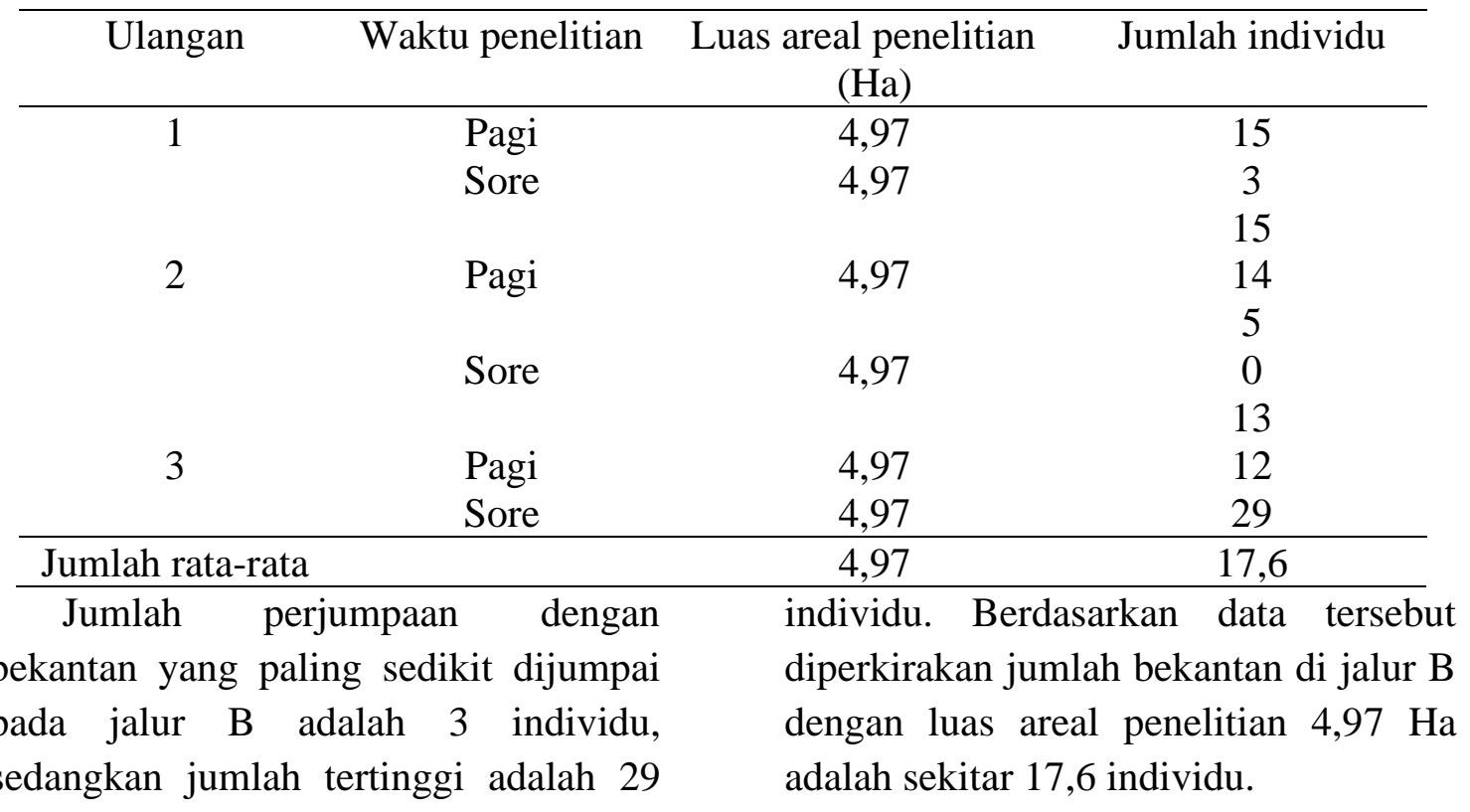


Tabel 3. Jumlah individu bekantan (Nasalis larvatus) pada jalur C. The number of Bekantan (Nasalis larvatus) on line C).

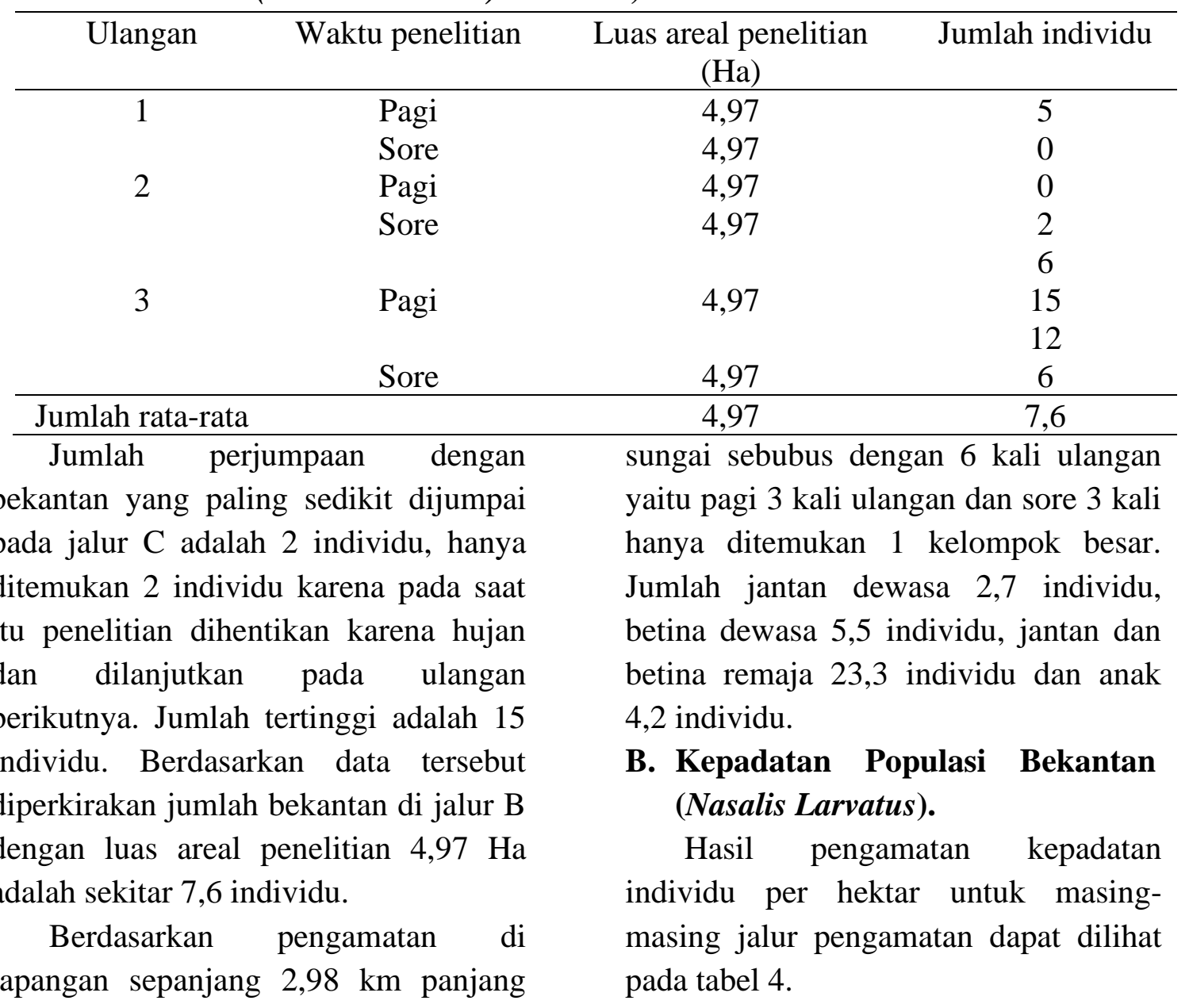

Tabel 4. Pendugaan Kepadatan Individu/ha. (Estimation of individual density/ha).

\begin{tabular}{ccc}
\hline Nama jalur & Luas jalur pengamatan $(\mathrm{Ha})$ & Kepadatan individu \\
\hline A & 4,97 & 5,3 \\
B & 4,97 & 8,8 \\
C & 4,97 & 3,8 \\
\hline
\end{tabular}

Tabel 4 dapat dilihat bahwa kepadatan individu bekantan yang terlihat pada areal penelitian yang luasanya 4,97 Ha pada jalur A adalah 5,3 individu/Ha pada jalur $\mathrm{B}$ adalah 8,8 individu/Ha dan pada jalur $\mathrm{C}$ adalah 3,8 individu/Ha. Jalur A, B dan C kepadatan individunya 17,91 individu/14,91 ha. Kepadatan individu yang ditemukan pada seluruh jalur pengamatan 1,2 individu/ha. Populasi bekantan yang ditemukan pada kawasan hutan mangrove Desa Sebubus yang luasnya 35 ha adalah 42 individu. Kepadatan kelompok bekantan yang terlihat pada seluruh areal penelitian yang luasanya 14,91 Ha adalah 0,50 kelompok, sedangkan kepadatan kelompok pada kawasan hutan mangrove Desa Sebubus yang luasannya 35 ha adalah 1,05 kelompok.

Nilai kepadatan suatu individu dan kelompok populasi yang terdapat didalam 
suatu kawasan menunjukan seberapa besar tingkat daya dukung suatu kawasan mampu mendukung kehidupan satwa tersebut. Nilai kepadatan tersebut diperlukan sebagai cermin dari kondisi daya dukung (Carring capacity) suatu habitat dalam suatu kawasan yang jelas. Semakin tinggi nilai kepadatan maka kondisi daya dukung habitatnya juga tinggi sehingga mampu mendukung sejumlah individu tertentu untuk dapat hidup dan bersaing didalamnya (Rizal, 2016). Ancaman terbesar terhadap kehidupan bekantan adalah menurunnya luas dan kualitas habitatnya. Perubahan tersebut terutama diakibatkan oleh penebangan kawasan hutan untuk dikonversi menjadi lahan pertanian, pemukiman penduduk, pertambakan (ikan dan udang). Kepadatan kelompok bekantan yang terlihat pada areal penelitian yang luasanya 14,91 Ha adalah 0,50 kelompok.

\section{KESIMPULAN}

Berdasarkan hasil dan pembahasan tentang populasi bekantan di kawasan hutan mangrove Sungai Setingga Asin Desa Sebubus maka dapat disimpulkan :

1. Jumlah bekantan yang ditemukan di sepanjang hutan mangrove Sungai Setingga Asin Desa Sebubus sebanyak 35,8 individu dengan jumlah kelompok sebanyak 1 kelompok. Jumlah jantan dewasa 2,7 individu, betina dewasa 5,5 individu, jantan dan betina remaja 23,3 individu dan anak 4,2 individu.

2. Kepadatan individu pada seluruh jalur pengamatan 1,2 individu/ha sedangkan kepadatan kelompoknya 0,03 kelompok/ha. Populasi bekantan yang ditemukan pada kawasan hutan mangrove Desa Sebubus yang luasnya 35 ha adalah 42 individu.

\section{SARAN}

Perlu monitoring populasi bekantan setiap tahunnya untuk mengetahui jumlah populasi bekantan apakah mengalami peningkatan atau penurunan.

\section{UCAPAN TERIMA KASIH}

Kami ucapkan terimakasih kepada bapak Darmawan selaku ketua pengelola LSM 'Kalilaek dan Green Leaf' yang telah memberikan izin dan bantuan fasilitas selama kegiatan pengamatan bekantan (Nasalis larvatus, Wurmb) di hutan mangrove Desa Sebubus.

\section{DAFTAR PUSTAKA}

Iskandar S, H S. Alikodra, M Bismark dan A P Kartono. 2017. Status Populasi dan Konservasi Bekantan (Nasalis larvatus, Wurmb.1787) di Habitat Rawa Gelam, Kalimantan Selatan. Jurnal Penelitian Hutan Dan Konservasi Alam 14 (2) : 123 -132 .

Rizal M, B Nurdjali dan H Prayogo. 2016. Populasi Bekantan (Nasalis larvatus, Wurmb) di Kawasan Hutan Sungai Kepuluk Desa Pematang Gadung Kabupaten Ketapang Kalimantan Barat. Jurnal Hutan Lestari 4 (4) : 564 569.

Sha J C M, H Bernard dan S Nathan. 2008. Status and conservation of proboscis monkeys (Nasalis larvatus) in sabah, east Malaysia. Jurnal Primate Conservation 23 (1) : $107-120$.

Tobing S L I. 2008. Teknis Estimasi Ukuran Populasi Suatu Jenis Primata. Jurnal Vis Vitalis, 1 (1) : 43-53. 